\title{
How Incorporating e-Learning into the Mathematics Curriculum Could Improve Indigenous Students' Achievement
}

\author{
Reshmi Salini Ratnam Lakhan and Kumar Laxman
}

\begin{abstract}
This paper looks at global indigenous students' underachievement in secondary mathematics when compared to other ethnicity students. Altogether fifteen independent studies and existing meta-analysis were analyzed through conducting a critical meta-analysis. During this process, indigenous students' learning styles, effective mathematical pedagogy and benefits of technology inclusion for indigenous students were considered.

It was found that indigenous students do not find western curriculum as relevant for them and are disengaged in the classroom. A culture inclusive curriculum through collaboration on tasks is vital. Technology allows collaboration on tasks, suits different learning styles and could lead onto increased motivation and mathematical achievement.
\end{abstract}

Index Terms-Culture inclusive curriculum, e-learning, indigenous students, ubiquitous learning.

\section{INTRODUCTION AND BACKGROUND}

\section{A. Introduction}

Academic achievements of Maori students' are low compared to the rest of the New Zealand students in all sectors of education. Underachievement in mathematics could be due to many different factors including the nature of this subject itself [1], [2], its pedagogy [1]-[3] and/or how it is assessed [4].

Effective teaching could mean relating this subject's contents to students' cultural backgrounds [5], [6] using technology. It could be effective in Maori [7], [8] as well as other indigenous students' learning due to collaboration on tasks [9].

\section{B. Rationale}

Indigenous students work well using a culture inclusive pedagogy through student centered approaches [10]. Students are digital citizens and their learning should be technology inclusive [11]. Despite Te Kotahitanga's many benefits for Maori students, it is still difficult to motivate and engage them in most class activities and thus their achievement rate is low.

This study is a critical review literature of how technology inclusion in education has improved the achievement of indigenous students around the world as it could provide opportunities for Maori students to collaborate, share and build on their mathematical knowledge while improving

Manuscript received May 5, 2017; revised October 24, 2017.

The authors are with University of Auckland, New Zealand (e-mail: thelakhans@gmail.com, haribol.kumar@gmail.com). motivation, engagement and mathematical achievement [8].

\section{Research Questions}

1) How well do indigenous students perform academically in mathematics, particularly within a New Zealand context?

2) How can e-learning/ m-learning benefit indigenous secondary students' mathematical learning, particularly within a New Zealand context?

\section{Methodology}

\section{A. Rationale for a Critical Meta-Analysis}

During this study, advantages of technology inclusion in the subject of mathematics was researched with particular emphasis on secondary school indigenous students' learning worldwide. It was investigated why indigenous students have different learning needs and styles from the rest of the students, what effective pedagogy means for them and does mathematics differ from other subjects. The result of different beliefs and its effect on mathematics teaching and learning was also determined.

\section{B. Search Process}

To search for relevant studies, different databases such as ERIC, Google Scholar, ProQuest, WorldCat, EBSCOhost, ScienceDirect, SAGE Journal Online, JSTOR and professional publishers Science direct Elsevier, Springer Link and Wiley were searched. Sourced articles were peer reviewed journals that were published in English. Search terms included keywords "e-learning", "indigenous students' achievement", "m-learning or mobile learning", "mathematics achievement for secondary students", and "Maori achievement in mathematics". Together with peer reviewed online journals, e-reports and e-books were also sourced using similar keywords.

\section{Selection Criteria}

All articles that were on indigenous students' mathematical teaching and learning or on indigenous students with or without technology use were initially chosen. Articles about secondary students are included but studies on preschool and university teaching and learning were excluded. Exceptions were made with articles on indigenous students learning or mathematics learning if done in both primary and secondary schools. For example, [1], [12]-[14]. Ref. [15] on remote indigenous students' understandings of measurement concepts and [16] on constructivists' and 
transmission views of mathematics teaching are both primary school based but were included as they had insights into contextual and pedagogical understanding.

Initially, it was decided to select articles in the period 2000 to 2016 to have up to date information as technology is rapidly advancing. However, [16] was selected as it looks at mathematical pedagogy and does not involve any technology use. Together with this, [2] and [4] do not clearly state its research details like sample size, type of instrument used and so on thus their validity and reliability could be questioned. However, they are selected as they both give insights into issues in mathematics learning and on indigenous knowledge and how culture could influence research data.

As the research question is about secondary school students, all articles from non-educational backgrounds were excluded. The initial search was also conducted on indigenous students' different learning needs and effective pedagogy for them. During this search, Maori achievement rate and their unique learning needs were also researched and how online learning could reinforce Te Kotahitanga principles to assist in Maori achievement. Inclusion and exclusion of articles at the beginning were done generally after reading the titles and the abstracts of the studies found.

\section{The Coding Process}

Once an article was selected, annotated bibliography was done and tabulated. Then the studies were coded individually using the following criteria - If the study is focused on students (St), teachers ( $\mathrm{T})$, indigenous (I), other ethnicities (OE), Maori (MR), primary (P), secondary (S), Mathematics (Mt), using technology (T) or other subjects (OS). Also the research methods was coded as mixed $(\mathrm{M})$, quantitative (Qn) or qualitative (Q). After reading an article, a brief description was written about its contents including any themes or patterns. These articles theories and findings were then compared with other chosen articles findings and themes to organize it into recurrent themes and other related themes to try and answer the current research question posed.

\section{DISCUSSION}

\section{A. Indigenous Students' Learning Needs through a Culture Inclusive Curriculum}

Culture inclusive pedagogy is using students' cultural heritage and building positive relationships for students to learn effectively. Ref. [2], [4], [15], [17] highlighted the importance of the context of a problem. It should be taken from a students' cultural heritage for better comprehension of the problem.

Ref. [15] is about using students' mathematical identities which includes their understanding, abilities, opinions and prior mathematical capabilities. It uses "Building on" as a mathematical pedagogy. However, the fact that indigenous ways to answer even a contextual question may be different to western ways or what assigned mathematical tasks intend to do. For instance, the units used in measuring distance could be in terms of time such as in minutes rather than in kilometers or temperature measurements could be using words such as "hot" or "cold" rather than in numerical terms or by using SI units.

Ref. [2] and [15] state that choosing mathematical practices to teach mathematical concepts is not simple as it needs careful consideration and respect. Some knowledge is meant to be shared with chosen individuals only and that indigenous knowledge is holistic in nature and should not be fragmented [2], [17].

Building positive student teacher relationships is also part of the culture inclusive pedagogy. This creates an effective classroom through respect [18] and care [10]. However, showing care could be different in different cultures [10].

Ref. [2] points out that teacher interaction affects mathematics teaching and learning. Ref. [16] and [18] mention that effective teaching happens when teachers create constraints in students' thinking through questioning for students to modify their ways of thinking. This builds positive student teacher relationships [8], [10], [12], [18].

\section{B. Perceptions of Different Parties Affecting Pedagogy}

Six of the study's findings include perceptions of students, teachers and parents. Ref. [2] discusses how parents, teachers and students different perceptions could affect mathematical learning. It mentions that parents' perception could influence the importance that their children associate with mathematical learning and if teachers think that this subject is value free than it would be taught without any historical, political or cultural inclusion through rote learning methods.

Ref. [18] states both students and teachers thought that teachers were respectful if they were well prepared, provided feedback on answers and errors and were punctual. To add on, they needed to use students' first names, be humorous and informal. However, students also thought that teachers should be approachable and this ties in with positive student teacher relationships.

\section{Technology Inclusion to Assist Indigenous Students' Learning Needs}

Technology use allows ubiquitous learning in different learning contexts [19]. It permits context aware learning due to global positioning system, wireless internet connection or cellular network and mobile apps [20]. Thus it could be useful for "placed based learning" mentioned in Ref. [4] and [17] due to the location-awareness feature of these devices.

\section{Technology Enhancing Mathematics Pedagogy}

Mathematics is thought to be a hierarchical subject with abstract contexts and has been set out in different stages according to different ages of students. Textbook authors and teachers sometimes decide on this sequence [2] that according to them is effective. The topic of measurement is thought to be effective if taught in a sequence [15].

However, technology assists mathematical understanding by making abstract concepts concrete [13]-[14], [19]. Ref. [2] states that technology inclusion allows mathematics to be studied as interconnected ideas rather than as learning in a sequence where some concepts have to be learnt first before others could be understood.

\section{E. Trend in the Use of Technology in Education}

Even though technology inclusion benefits education and its overall use has increased [14], there still needs to be more 
awareness of its benefits in education especially in the secondary schooling sector. There are more research conducted in the use of technology in learning in 2006 to 2010 and this increased steeply after 2009. However, these research were mostly done in the tertiary sector $(51.98 \%)$ followed by primary $(17.51 \%)$ and secondary schools $(8.47 \%)$ [21]. In [22], articles were collected from 2001 to 2010 about technology use in education. They also noticed the number of articles increased after 2008 but 59 articles were on higher education, 41 on elementary schools and 17 on high school.

Ref. [22] also mentioned that articles investigating students' motivation, perception and attitude due to technology enhanced learning increased from 13 articles in the period 2001 to 2005 to 36 articles from 2006 to 2010. However, mathematics was the least researched out of 7 learning areas with only 6 articles found on it. In [21], mathematics is categorized under formal sciences which was the third highest researched area with 26 articles after Professions and Applied Sciences (51) and Humanities (36). However, out of these 26 articles, only 3 were on mathematics and 23 on computer sciences.

Research on technology use in secondary education is not significantly high even though overall technology use has rapidly increased. There needs to be more research conducted on how technology use could benefit secondary school students' learning, especially in mathematics. Out of the 15 articles studied, only [9] and [14] articles reported a direct link of technology inclusion (CT) affecting mathematical achievement. Using virtual manipulatives to explain abstract mathematical concepts and using engaging video and multi-media computing technology to simulate problem settings could assist students to develop problem solving and critical thinking skills. However, these improved results were mentioned as not being consistent with all the other articles that were looked at due to other dependent factors including motivation and poor attendance [9].

Teachers need relevant professional developments on not only how to integrate technology into their lessons but towards getting technologically literate. In order to become effective teachers they need a wide range of technological tools that they could select from and not have a narrow range of choice. Technology is rapidly advancing means teachers need to be able to use new software that could be beneficial for a subject and year level rather than just trying to use what they can in all lessons and grade levels [23].

\section{F. Mathematics Achievement and the Assessment Tool}

"Mathematics achievement refers to performance scores (on solving mathematical problems) that are measured by mathematics tests, either standardized ones or teacher-made (researcher-made) ones" ([14], p.218). Ref. [13], [14] state that using computer technology and learning objects respectively does improve mathematical achievement but if other factors are also considered.

Similarly, achievement due to technology was also mentioned in [9]. However, success was mentioned as dependent on other factors as well such as poor attendance, social and personal challenges, student motivation, and time management skills. Together with this, [14] found that mathematics achievement using CT was higher when used in a Constructivist's environment using small group activities. This allowed collaboration on tasks than in a Behaviorist's one where it was teacher centered and as a whole class activity. This means results also depend on how it is used rather than just the use of technology.

\section{GAPS IN THE SELECTED ARTICLES}

Even though teachers' role has changed due to technology inclusion in the educational context, their active presence is still vital [8], [9], [12]. However, teachers need to know how to include technology successfully into their subject disciplines and how to consider other essential factors while doing so successfully. For instance, they need to know how their students learn especially the indigenous students. There is a need for professional development opportunities for teachers in order to improve their pedagogy. Ref. [12] states these sessions need to be on effectively using e-learning tools and on how to improve students' online work ethics. As for indigenous Maori students, [10], thinks it should be on successful integration of Durie's (1998) Model representing the four walls of a mathematics classroom signifying aspects of health and well-being. Ref. [18] thinks a professional development is needed to improve teacher confidence in using culture inclusive curriculum. However, technology is advancing very rapidly [20] and only teaching use of certain software, hardware and terminology to teachers will not help. Teachers need to possess a wide range of technological tools in order to suit their students' learning needs [12].

Other issues raised for indigenous students' learning are how teachers could show caring practices in a classroom as these practices change as students move from preschool through to tertiary education. These practices are also affected by gender differences [10]. To add on, respect in the classroom differs due to difficult student behavior, different ability levels of students in a class and curriculum pressure [18]. Ref. [8] states that technology could allow students to bring their culture into the classroom. However, not enough studies are conducted on the level of mathematical understanding students bring into the classroom as their prior knowledge [15] and if this prior knowledge could be used effectively to teach mathematics to them [2]. Ref. [2] and [15] state that it cannot be said with certainty if having a familiar context to a problem is going to lead to successful learning. According to [17], learning from place should not be generalized for all Aboriginal students even though it did work for the students in the particular context of the study.

Ref. [15] says that there is a need for more articles on indigenous perspective about indigenous knowledge as they are non-indigenous researchers. Ref. [12] puts forward a need for comparing Maori and non-Maori students' perceptions on effectiveness of learning through virtual learning networks. They also mentioned limited e-learning research done on Maori students or in a Maori environment.

Ref. [8] states that more research on the benefits of technology has been done on primary schools than on secondary school students. She also questioned if technology benefits would be the same for different gender, teacher knowledge and availability of professional development. To add on, if the language of students, whether they are bilingual 
or not, has any effect on them benefitting from technology use.

\section{IMPLICATIONS FOR MAORI STUDENTS}

\section{A. Maori and What Works for Them}

Maori are the indigenous people of New Zealand and they show a similar trend in mathematical learning as other indigenous students globally. They do not find western knowledge as relevant to them and lack of motivation and engagement in the classroom has created underachievement [5].

Ref. [24] mentions that the number of articles written on the subject of equity and/or social justice in education has increased. Schools need to provide an effective education through an equitable education for all as classrooms are diverse in nature now. During student teacher interactions unequal treatment of Maori students is visible. In a study conducted by Marie Clay mentioned in [24], it was found that 'Pakeha' teachers preferred non-Maori students to answer in class discussions over Maori students. Maori students work better in collaboration than as individuals and prefer to be silent and not give out answers during class discussions.

To make education relevant for these students, a culture inclusive curriculum should be designed while keeping these students' different learning needs in mind. A culture inclusive curriculum for Maori students will mean demonstrating characteristics of teacher care as mentioned in a New Zealand school reform called "Te Kotahitanga". It highlights the need for a strong positive relationship between teachers and their students as the key to success. Positive relationships improve students' motivation, engagement and achievement [6], [10].

\section{B. How Technology Could Benefit Maori Students}

Using technology could be one of these effective teaching approaches. It is cheaper especially mobile devices like a smartphone and thus it is affordable. Maori people use mobile phones more than non-indigenous people [25].

Technology is not only affordable but allows personalized and collaborative learning opportunities, improves engagement and motivation on tasks and permits ubiquitous learning and thus learning becomes relevant [26]. Its use is suitable for Maori learners [12]. This method of forming a community of learning works for the Maori students [7], [8]. Online learning could address this issue as interactions between students and teachers increases. Thus greater possibility of one to one interaction needed for Maori students' learning [12], [18] despite large class sizes.

Attendance of Maori students is not very good and this could be due to whanau responsibilities. Technology could allow learning to be flexible for them as it could be done from home [7]. There is also possibility of context aware learning which could be used for placed based learning. This approach has been identified as advantageous for indigenous learners due to learning from the land. Land is sacred for all indigenous students [4], [17] including Maori students.

According to [12] and [27] technology inclusion could improve student teacher relationships. Both teachers and students would be equal online [12]. This means it could reinforce Te Kotahitanga principles and thus a culturally inclusive curriculum for Maori students. This in turn makes learning engaging, motivating and according to [8], [10], and [18] could lead to mathematical achievement. Effective instructions could be delivered using audio and/or visual methods making it attractive to even the reluctant Maori learners.

Context aware learning and mobile social learning environments could improve student teacher relationships [19] and could create effective learning for Maori students [2], [8]. Ref. [19] makes reference that to be socially connected allows collaborative and interactive learning environment. Ref. [12] points out that this environment allows Maori students and teachers to be co-learners. Thus allows the concept of "Ako" which has been mentioned as one of the aspects of demonstrating teacher care.

Technological and pedagogical knowledge of teachers improves [9]. Teachers' role would change as now they are facilitators and do not only give direct instructions. However, their active presence is still important [8], [9]. Together with this, context aware learning, allows students to bring their culture into the classroom, experience learning on the go and learn contextual information while on a particular site. This means learning could be relevant and flexible for students as it could happen when needed and from anywhere.

\section{CONCLUSION}

There is mathematics underachievement for the indigenous students around the world including New Zealand Maori students. It is a value laden subject and its pedagogy is also influenced by students' and teachers' different cultural beliefs.

This underachievement could as well be due to the abstract context of the subject. Technology enhances mathematical pedagogy due to the simulation of activities that allow learners to understand abstract mathematics concepts. Besides mathematics no longer needs to be taught as sequential but through building on students' prior knowledge which could be possible through using technology. However, some difficulties could still be present. These could be the irrelevant assessment tools used to assess indigenous students' achievement.

A culture inclusive curriculum has the potential to benefit indigenous students' mathematical learning. Thus it could also improve Maori students' mathematical achievement through incorporating technology.

\section{REFERENCES}

[1] N. Y. Wong, "Conceptions of doing and learning mathematics among Chinese," Journal of Intercultural Studies, vol. 23, no. 2, pp. 211-229, 2002.

[2] T. Meaney, "Symbiosis or cultural clash? Indigenous students learning mathematics," Journal of Intercultural Studies, vol. 23, no. 2, pp 167-187, 2002.

[3] W. T. Seah, "The Perception of, and interaction with, value differences by immigrant teachers of mathematics in two Australian secondary classrooms," Journal of Intercultural Studies, vol. 23, no. 2, pp. 189-210, 2002.

[4] E. Abrams, C. P. Taylor, and C. Guo, "Contextualizing culturally relevant science and mathematics teaching for indigenous learning," 
International Journal of Science and Mathematics Education, vol. 11 no. 1, pp. 1-21, 2013.

[5] R. Bishop and M. Berryman, "The Te Kotahitanga effective teaching profile," New Zealand Council for Educational Research, vol. 2, pp. 27-33, 2009.

[6] A. R. Bishop, M. A. Berryman, J. B. Wearmouth, and M. Peter, "Developing an effective education reform model for indigenous and other minoritized students," School Effectiveness and School Improvement: An International Journal of Research, Policy and Practice, vol. 23, no. 1, pp. 49-70, 2012.

[7] A. Datt., C. Donald, and S. Carter, "Engaging students online: "E ako!" Mai Review Journal, vol. 3, pp. 1-4, 2011.

[8] N. Wright, E-Learning and Implications for New Zealand Schools: A Literature Review, Ministry of Education, 2010.

[9] D. Philpott, D. Sharpe, and R. Neville, "The effectiveness of web-delivered learning with aboriginal students: Findings from a study in coastal Labrador," Canadian Journal of Learning and Technology, vol. 35, no. 3, pp. 1-14, 2009.

[10] R. Averill, "Caring teaching practices in multiethnic mathematics classrooms: attending to health and well-being," Mathematics Education Research Journal, vol. 24, no. 2, pp. 105-128, 2012.

[11] F. Ozdamli and H. Uzunboylu, "M-learning adequacy and perceptions of students and teachers in secondary schools," British Journal of Educational Technology, vol. 46, no. 1, pp. 159-172, 2014.

[12] C. Bennett and M. K. Barbour, "The FarNet journey: Perceptions of Maori students engaged in secondary online learning," Journal of Ope n, Flexible and Distance Learning, vol. 16, no. 1, pp. 83-98, 2012.

[13] R. Kay and L. Knaack, "Investigating the use of learning objects for secondary school mathematics," Interdisciplinary Journal of e-Learning and Learning Objects, vol. 4, pp. 269-289, 2008.

[14] Q. Li and X. Ma, "A meta-analysis of the effects of computer technology on school students' mathematics learning," Educational Psychology Review, vol. 22, no. 3, pp. 215-243, 2010.

[15] P. Grootenboer and P. Sullivan, "Remote indigenous students' understandings of measurement," International Journal of Science and Mathematics Education, vol. 11, no. 1, pp. 169-189, 2013.

[16] P. Cobb, "Tension between theories of learning and instruction in mathematics education," Educational Psychologist, vol. 23, no. 2, pp. 87-103, 1988.

[17] G. Sterenberg, "Considering indigenous knowledges and mathematics curriculum," Canadian Journal of Science, Mathematics and Technology Education, vol. 13, no, 1, pp.18-32, 2016.

[18] R. Averill and M. Clark, "Respect in teaching and learning mathematics: Professionals who know, listen to and work with students," Research Information for Teachers (Wellington), vol. 3, pp. 50-57, 2012.

[19] Z. Taleb, A. Ahmadi, and M. Musavi, "The effect of m-learning on mathematics learning," Procedia- Social and Behavioral Sciences, vol. 171, pp. 83-89, 2015.

[20] Y. C. Hsu and Y. H. Ching, "A review of models and frameworks for designing mobile learning experiences and environments," Canadian Journal of Learning and Technology, vol. 41, no. 3, pp. 1-22, 2015.

[21] W. Wu, Y. Jim Wu, C. Chen, H. Kao, C. Lin, and S. Huang, "Review of trends from mobile learning studies: A meta-analysis," Computers \& Education, vol. 59, no. 2, pp. 817-827, 2012.

[22] G. Hwang and C. Tsai, "Research trends in mobile and ubiquitous learning: A review of publications in selected journals from 2001 to 2010," British Journal of Educational Technology, vol. 42, no. 4, pp. E65-E70, 2011.

[23] M. J. Koehler., P. Mishra, and K. Yahya, "Tracing the development of teacher knowledge in a design seminar: Integrating content, pedagogy and technology," Computers \& Education, vol. 49, no. 3, pp. 740-762, 2007.

[24] B. Kaur, "Equity and social justice in teaching and teacher education," Teaching and Teacher Education, vol. 28, no. 4, pp. 485-492, 2012.

[25] L. E. Dyson and A. Litchfield, "Advancing collaboration between m-learning researchers and practitioners through an online portal and Web 2.0 technologies," International Journal of Mobile and Blended Learning, vol. 3, no. 1, pp. 64-72, 2011.

[26] M. Hashemi, M. Azizinezhad, V. Najafi, and A. J. Nesari, "What is mobile learning? Challenges and capabilities," Procedia - Social and Behavioral Sciences, vol. 30, pp. 2477-2481, 2011.

[27] S. Tosheva and C. Martinovska, "Adaptive e-learning system in secondary education," International Journal of Emerging Technologies in Learning (iJET), vol. 7, no. (S1), pp. 36-41, 2012.

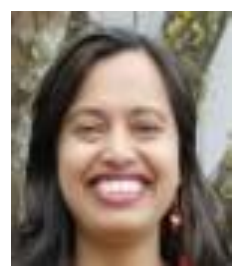

R. S. R. Lakhan was born in Fiji but migrated to New Zealand in 2006. She graduated with a bachelor of science in mathematics and physics in 1999 and later completed her post graduate certificate in education in 2005 from the University of the South Pacific in Fiji In 2017 , she graduated with a master of professional studies in education from the University of Auckland in New Zealand. The main focus of this study was to investigate if incorporating e-learning into the mathematics curriculum could improve indigenous students' achievement

In 2000, she started teaching mathematics and physics in Fiji. Currently, she is a mathematics teacher at a south Auckland school in New Zealand. 